\title{
Simultaneous middle Pleistocene eruption of three widespread tholeiitic basalts in northern California: Insights into crustal magma transport in an actively extending back-arc
}

Drew T. Downs*, Duane E. Champion, L.J. Patrick Muffler, Robert L. Christiansen, Michael A. Clynne, and Andrew T. Calvert

U.S. Geological Survey, California Volcano Observatory, 345 Middlefield Road, Menlo Park, CA 94025, USA

\section{SUPPLEMENTAL FILE \\ ${ }^{40} \mathrm{Ar} /{ }^{39}$ Ar Radiometric Dating}

Four samples with dense, crystalline groundmass were collected from the three tholeiitic basalt lava flows (one from the basalt of Tennant, one from the basalt of Dry Lake and two from the basalt of Hammond Crossing) for dating by the ${ }^{40} \mathrm{Ar} /{ }^{39} \mathrm{Ar}$ method. Each sample was crushed in a roller mill, washed in an ultrasonic bath, and sieved to the 250-355 $\mu \mathrm{m}$ size fraction. Approximately $150 \mathrm{mg}$ of fresh groundmass was separated using a LB-1 Barrier Frantz magnetic separator and handpicked to remove undesirable phases (e.g., phenocrysts, glass shards, altered groundmass). Groundmass separates were packaged in $\mathrm{Cu}$ foil along with Bodie Hills sanidine monitor minerals (9.797 Ma, equivalent to Fish Canyon sanidine at $28.106 \pm 0.012 \mathrm{Ma}$; Fleck and Calvert, 2016), and enclosed in quartz vials wrapped in $0.5 \mathrm{~mm}$ thick $\mathrm{Cd}$ foil to shield samples from thermal neutrons during irradiation. Samples were irradiated for 1 hour in the central thimble of the U.S. Geological Survey TRIGA reactor in Denver, Colorado at a power level of 1 MW (Dalrymple et al., 1981). The reactor vessel was rotated continuously and oscillated vertically during irradiation to minimize vertical and lateral neutron flux gradients.

Argon isotopic measurements were conducted at the U.S. Geological Survey in Menlo Park, California using a MAP216 single-collector mass spectrometer with a Baur-Signer source and a Johnston MM1 electron multiplier. Argon was extracted from Bodie Hills fluence monitor sanidines in a single heating step (i.e., total fusion) using a $\mathrm{New}$ Wave $\mathrm{CO}_{2}$ laser, whereas $\mathrm{Ar}$ was extracted from groundmass separates of unknown age in 7-10 temperature steps (typically spanning $550-1450^{\circ} \mathrm{C}$ ) using a Mo shielded custom resistance furnace with a Mo crucible. Extracted Ar was exposed to a 4 A tungsten filament, $-150^{\circ} \mathrm{C}$ cold finger, and two SAES St- 175 getters (one at $300^{\circ} \mathrm{C}$, one at room temperature) to remove active gases. Prior to measurement, samples were degassed at $500^{\circ} \mathrm{C}$ until troublesome gases (e.g., water, nitrogen, hydrocarbons as measured by a Granville-Phillips 835 VQM) were reduced to acceptable levels. Instrumental mass discrimination was calculated by repeated measurement of air, assuming atmospheric ${ }^{40} \mathrm{Ar} /{ }^{36} \mathrm{Ar}=298.56 \pm 0.31$ (Lee et al., 2006). Ages were calculated using the decay constants of Steiger and Jäger (1977). Uncertainties are reported at $1 \sigma$ unless otherwise stated and include propagated uncertainties in counting statistics and $\mathrm{J}$ values. Table 1 includes all relevant data for the ${ }^{40} \mathrm{Ar} /{ }^{39} \mathrm{Ar}$ analyses, and the full age spectra are provided in Figures S1-S4 (pink boxes indicate temperature steps used to calculate the plateau and isochron ages, whereas gray boxes indicate temperature steps excluded from calculating the plateau and isochron ages).

\section{Paleomagnetic Analysis}


Paleomagnetic samples were collected, processed and interpreted from 33 sites (18 from the basalt of Tennant, 11 from the basalt of Dry Lake and 4 from the basalt of Hammond Crossing) using standard protocols (McElhinny, 1973). Eight, 10-cm-long cores were drilled at each site using a portable, hand-held, gasoline-powered, water-cooled, diamond-coring drill and were oriented in the field using a sun compass. A $2.5 \mathrm{~cm}$ long specimen from each core was measured using a cryogenic magnetometer. All specimens were subjected to alternating-field (AF) demagnetization to remove secondary components of magnetization. An isothermal remanent magnetization resulting from nearby lightning strikes was a significant secondary magnetization source for some cores from most sites. The mean characteristic direction of remanent magnetization for each site was calculated using peak AF ties of 20-30 mT to generate line fits on vector-component diagrams or plane fits on equal-area diagrams. Line fits were averaged using conventional Fisher statistics. Some specimens failed to reveal their characteristic remanent magnetization through AF demagnetization and instead were fit with great-circle planes matching their progressive cleaning behavior. As a result, these sites were calculated using the intersection of planes data or a mixture of lines and planes data. Most sites have mean directions with $95 \%$ confidence limits between $1-3^{\circ}$. Site mean directions of magnetization for each group, including 95\% confidence limits, are provided in Table S1.

\section{X-Ray Fluorescence Spectrometry and Instrumental Neutron Activation Analysis}

Chemistry was used for correlations and determining if the magmas that fed these eruptions are related. Back-arc tholeiitic basalts (also commonly referred to as low-K olivine tholeiites or high-Al olivine tholeiites) in northern California have a unique chemical signature for each eruption, most likely controlled by degree, depth, and mineral composition of the melting metasomatized mantle lithosphere. To characterize these tholeiitic basalts, the majoroxide and trace-element abundances from 58 representative samples were compiled and examined. Of these samples, major-oxide and trace-element chemistry for 39 samples were analyzed as part of this study and 19 samples are provided in Donnelly-Nolan (2008). Table S2 provides a compilation of all samples analyzed as part of this study and from Donnelly-Nolan (2008).

All samples were chipped to $\leq 5 \mathrm{~mm}$ size and altered pieces were removed by hand. Samples were analyzed for major-oxide and trace-element abundances by wavelength-dispersive X-ray fluorescence (WD-XRF) spectrometry using the methods of Johnson et al. (1999). Fresh rock chips $(50 \mathrm{~g})$ were powdered in an $\mathrm{Al}$ ring mill, diluted with a flux of di-lithium tetraborate $\left(\mathrm{Li}_{2} \mathrm{~B}_{4} \mathrm{O}_{7}\right)$ at a 2:1 ratio of flux to rock and fused into a bead at $1000^{\circ} \mathrm{C}$. After cooling, the bead was powdered, refused and polished to provide a smooth surface for analysis of 10 major oxide and 19 trace elements. Nine of the samples were analyzed by this method on a ThermoARL Advant'XP+ sequential XRF spectrometer at the GeoAnalytical Laboratory at Washington State University in Pullman, Washington (https://environment.wsu.edu/facilities/geoanalyticallab/technical-notes/xrf-method/), whereas seven samples were analyzed by this method on a Thermo-ARLPerform'X XRF spectrometer at the Hamilton Analytical Laboratory at Hamilton College in Clinton, New York (https://www.hamilton.edu/academics/analyticallab/instrumentation).

Major-oxide analyses of 42 samples (19 from Donnelly-Nolan, 2008) were performed on pressed powder pellets by WD-XRF spectrometry at the U.S. Geological Survey Analytical Laboratory in Lakewood, Colorado (Taggart et al., 1987). Trace-element abundances were analyzed by energy-dispersive X-ray fluorescence (ED-XRF) spectrometry at the U.S. 
Geological Survey in Menlo Park, California (Webb et al., 1990). Precision has been determined by repeated analysis of internal standards (Bacon and Druitt, 1988).

Trace-element abundances for a suite of four samples (from Donnelly-Nolan, 2008) were measured by instrumental neutron activation analysis (INAA) at the U.S. Geological Survey in Reston, Virginia (Baedecker and McKown, 1987). Duplicate analysis of samples in both the U.S. Geological Survey and Washington State University laboratories show comparable accuracy.

\section{References Cited}

Bacon, C.R., and Druitt, T.H., 1988, Compositional evolution of the zoned calcalkaline magma chamber of Mount Mazama, Crater Lake, Oregon: Contributions to Mineralogy and Petrology, v. 98, p. 224-256, doi:10.1007/BF00402114.

Baedecker, P.A., and McKown, D.M., 1987, Instrumental neutron activation analysis of geochemical samples: U.S. Geological Survey Bulletin 1770, 14 p.

Dalrymple, G.B., Alexander, E.C., Jr., Lanphere, M.A., and Kraker, G.P., 1981, Irradiation of samples for ${ }^{40} \mathrm{Ar} /{ }^{39} \mathrm{Ar}$ dating using the Geological Survey TRIGA reactor: U.S. Geological Survey Professional Paper 1176, 55 p.

Donnelly-Nolan, J.M., 2008, Chemical analyses of pre-Holocene rocks from Medicine Lake Volcano and vicinity, northern California: U.S. Geological Survey Open-File Report 2008-1094, doi:10.3133/ofr20081094.

Donnelly-Nolan, J.M., 2010, Geologic map of Medicine Lake volcano, northern California: U.S. Geological Survey Scientific Investigations Map 2927, scale 1:50,000, 48 p. text.

Fleck, R.J., and Calvert, A.T., 2016, Intercalibration of ${ }^{40} \mathrm{Ar} /{ }^{39} \mathrm{Ar}$ mineral standards with Bodie Hills sanidine: Geological Society of America Abstracts with Programs, v. 48, doi:10.1130/abs/2016AM-286011.

Irwin, W.P., 2003, Correlation of the Klamath Mountains and Sierra Nevada: U.S. Geological Survey Open-File Report 02-490, 2 sheets.

Johnson, D.M., Hooper, P.R., and Conrey, R.M., 1999, XRF analysis of rocks and minerals for major and trace elements on a single low dilution Li-tetraborate fused bead: JCPDSInternational Centre for Diffraction Data, p. 843-867.

Lee, J.-Y., Marti, K., Severinghaus, J.P., Kawamura, K., Yoo, H.-S., Lee, J.B., and Kim, J.S., 2006, A redetermination of the isotopic abundances of atmospheric Ar: Geochimica et Cosmochimica Acta, v. 70, p. 4507-4512, doi:10.1016/j.gca.2006.06.1563.

McElhinny, M.W., 1973, Paleomagnetism and Plate Tectonics: Cambridge, United Kingdom, University Press, 368 p.

Steiger, R.H., and Jäger, E., 1977, Subcommission on geochronology: Convention on the use of decay constants in the geo- and cosmochronology: Earth and Planetary Science Letters, v. 36, p. 359-362, doi:10.1016/0012-821X(77)90060-7.

Taggart, J.E., Jr., Lindsey, J.R., Scott, B.A., Vivit, D.V., Bartel, A.J., and Stewart, K.C., 1987, Analysis of geologic materials by wavelength-dispersive X-ray fluorescence spectrometry: U.S. Geological Survey Bulletin 1770, 19 p.

Webb, P.C., Potts, P.J., and Watson, J.S., 1990, Trace element analysis of geochemical reference samples by energy dispersive X-ray fluorescence spectrometry: Geostandards Newsletter, v. 14, p. 361-372, doi:10.1111/j.1751-908X.1990.tb00077.x. 

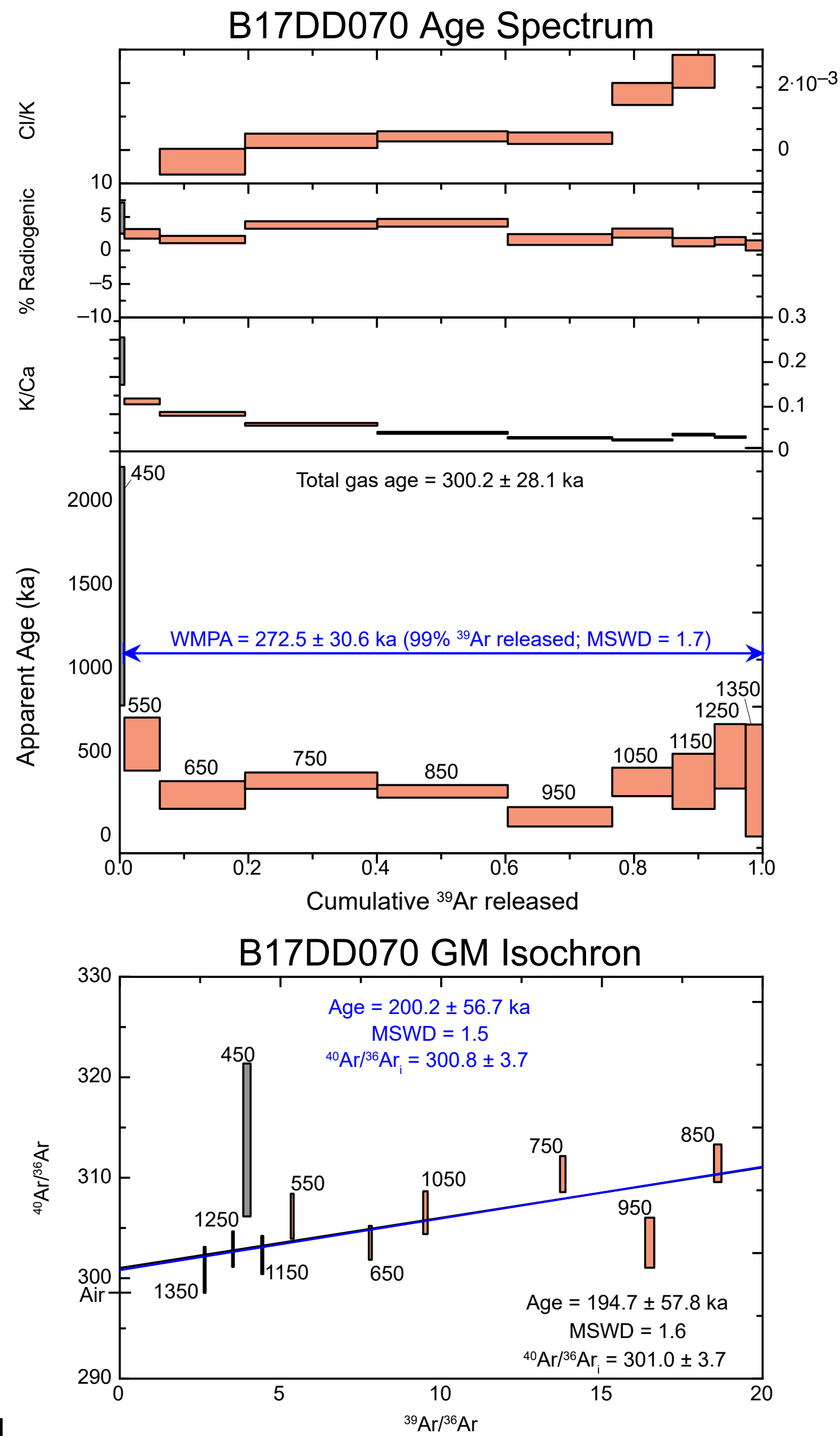
B16DD053 Age Spectrum

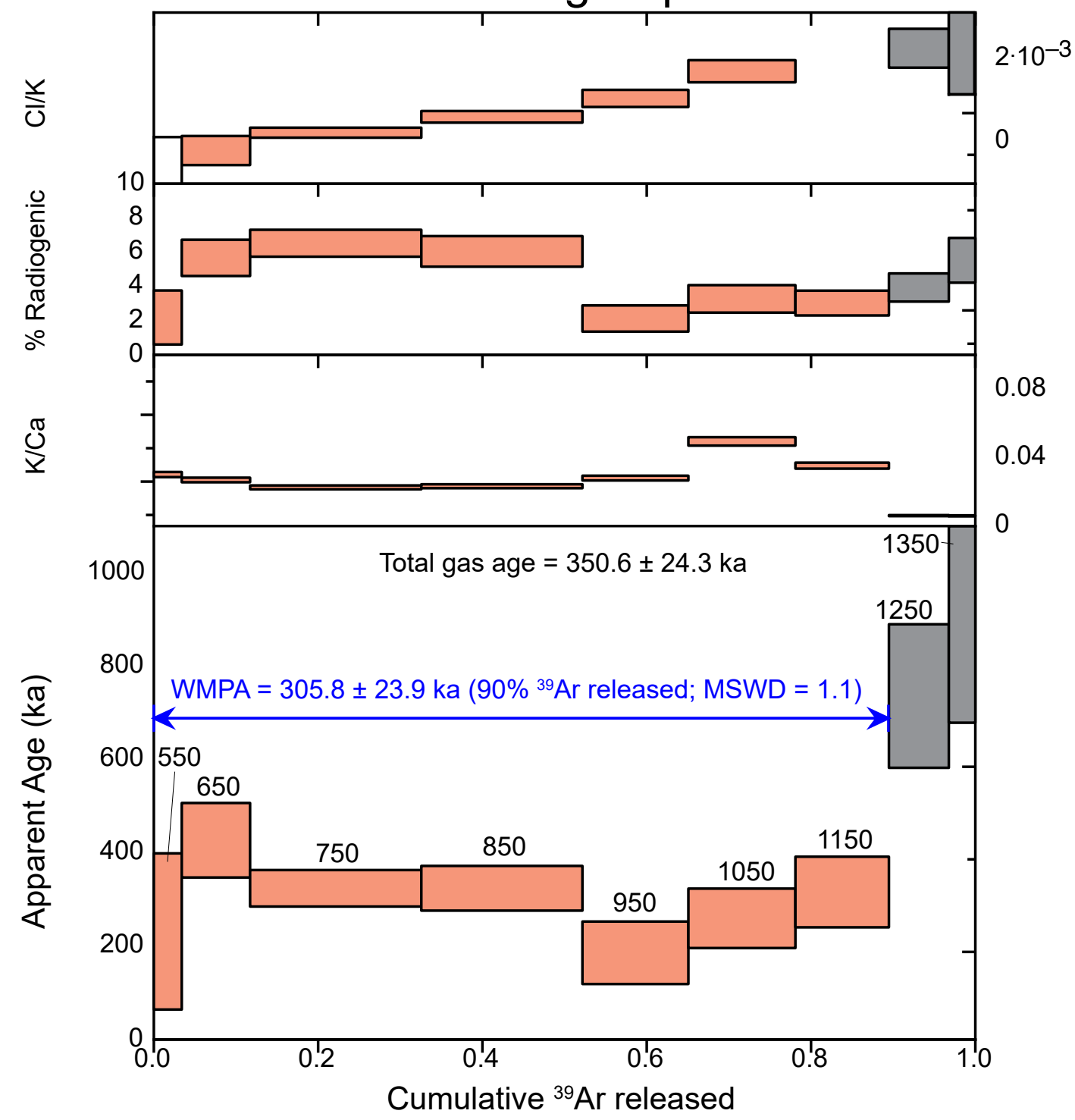

Figure S2

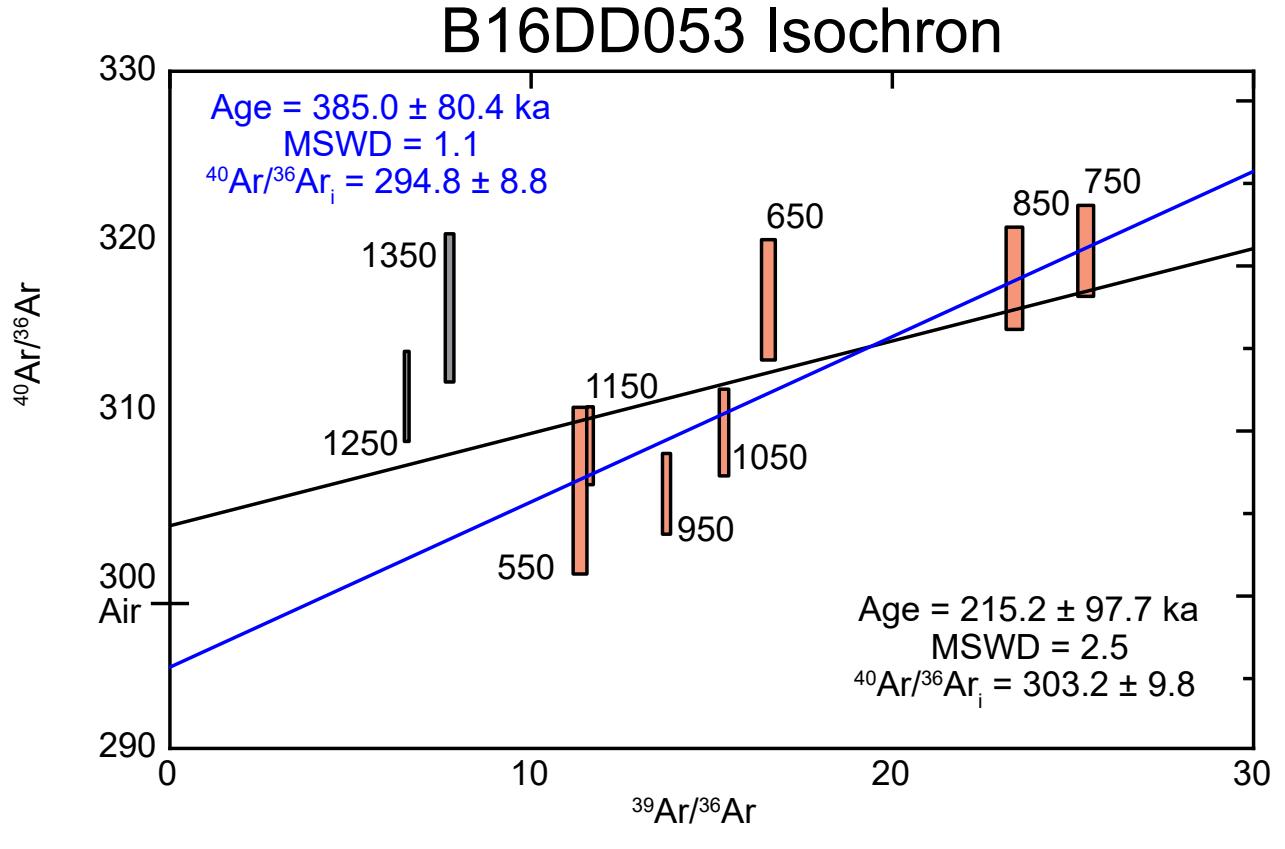


B15DD005B Age Spectrum

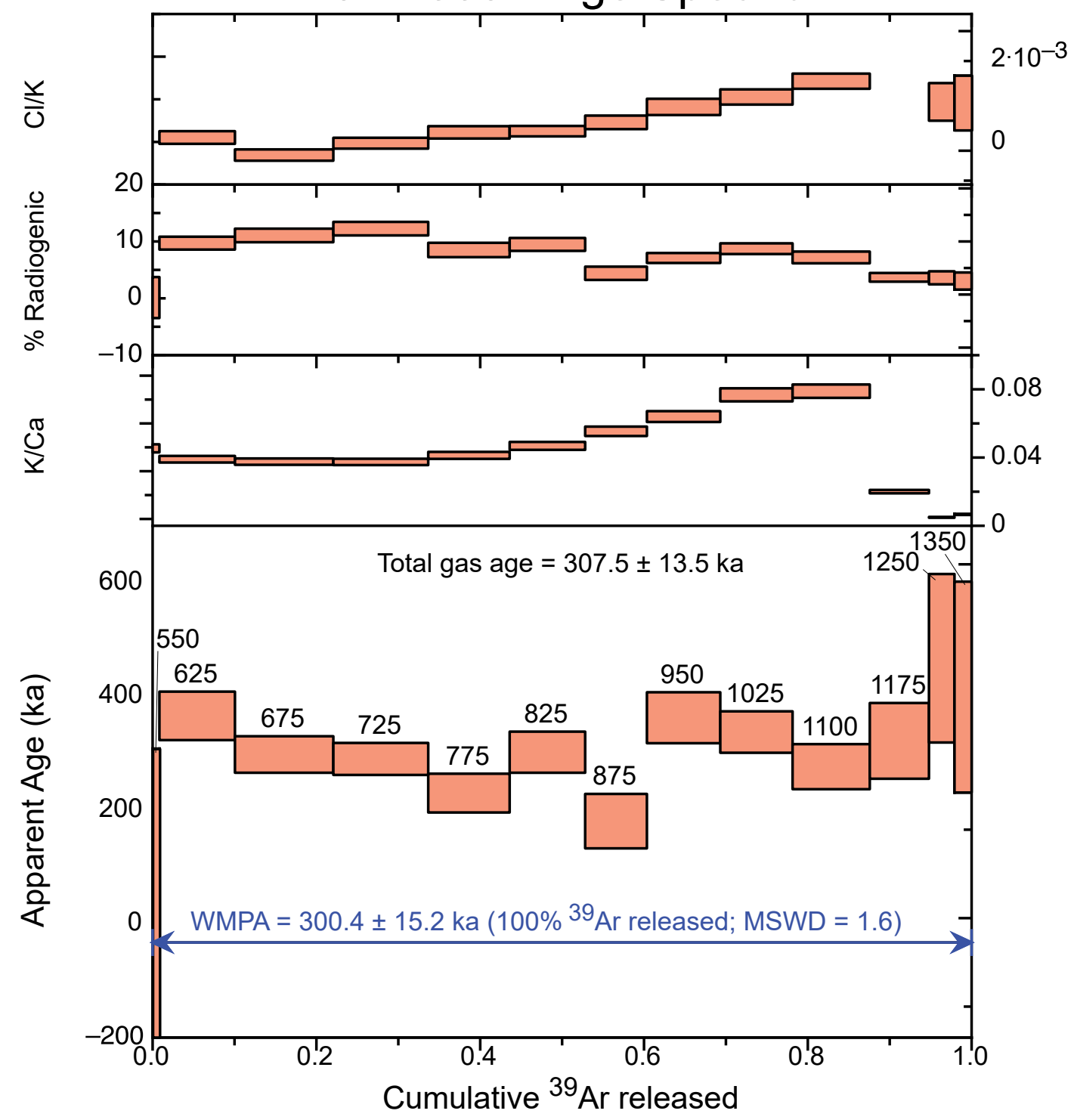

B15DD005B Isochron

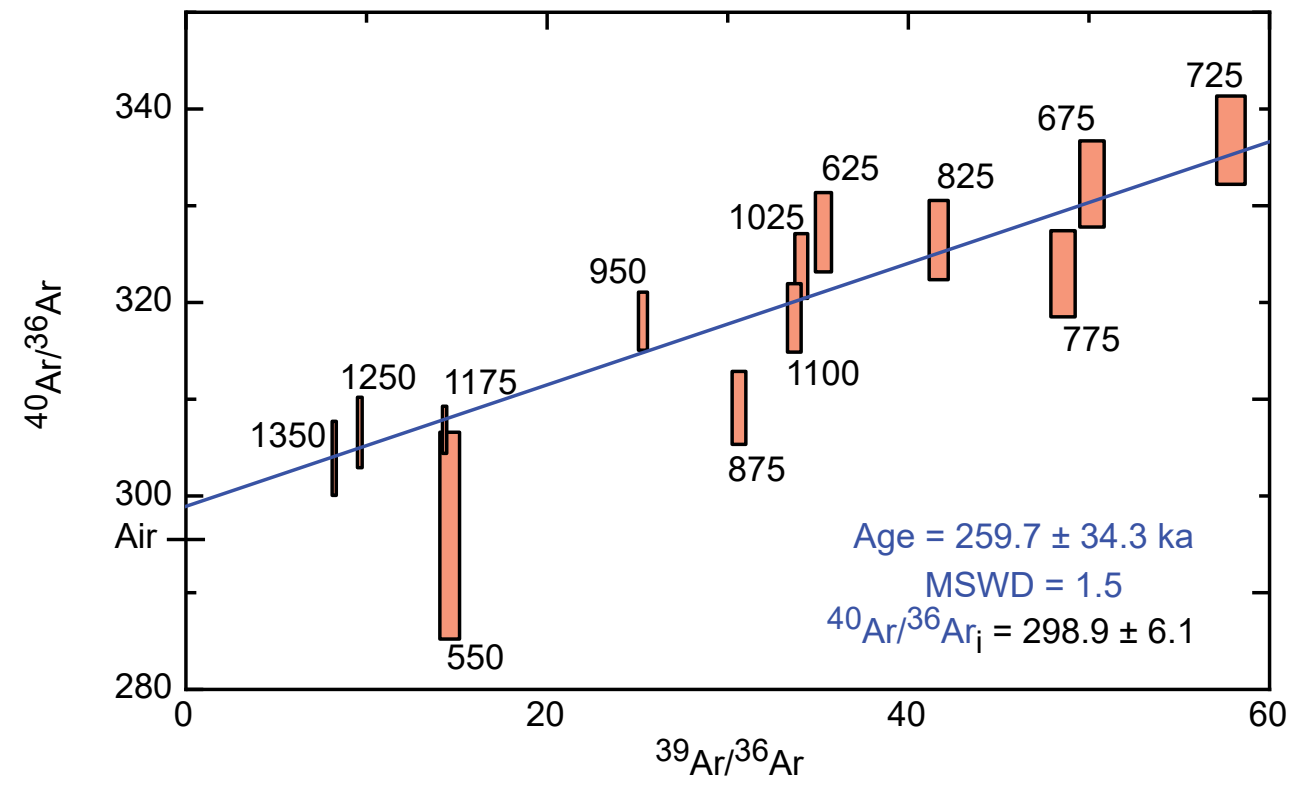

Figure S3 


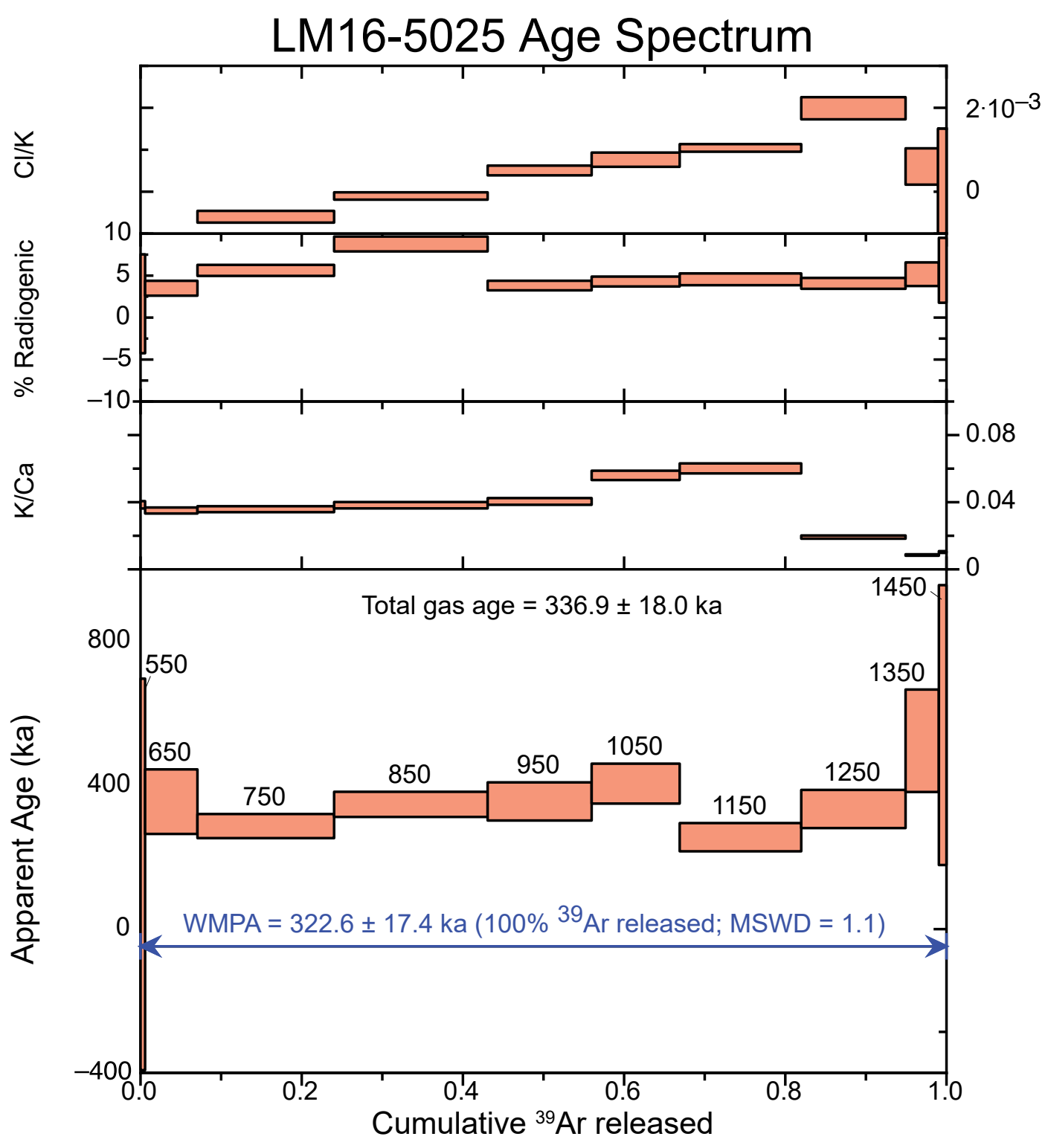

Figure S4

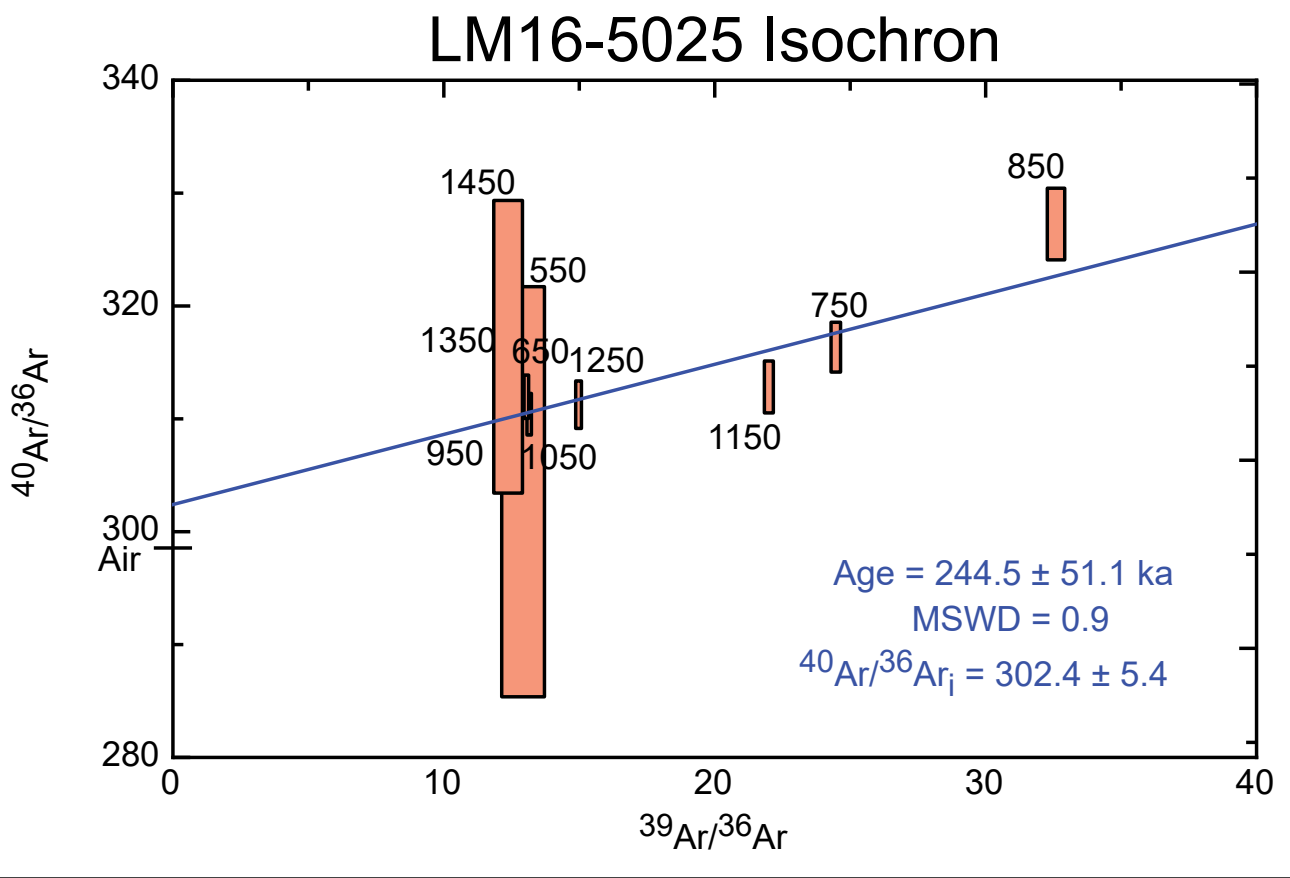




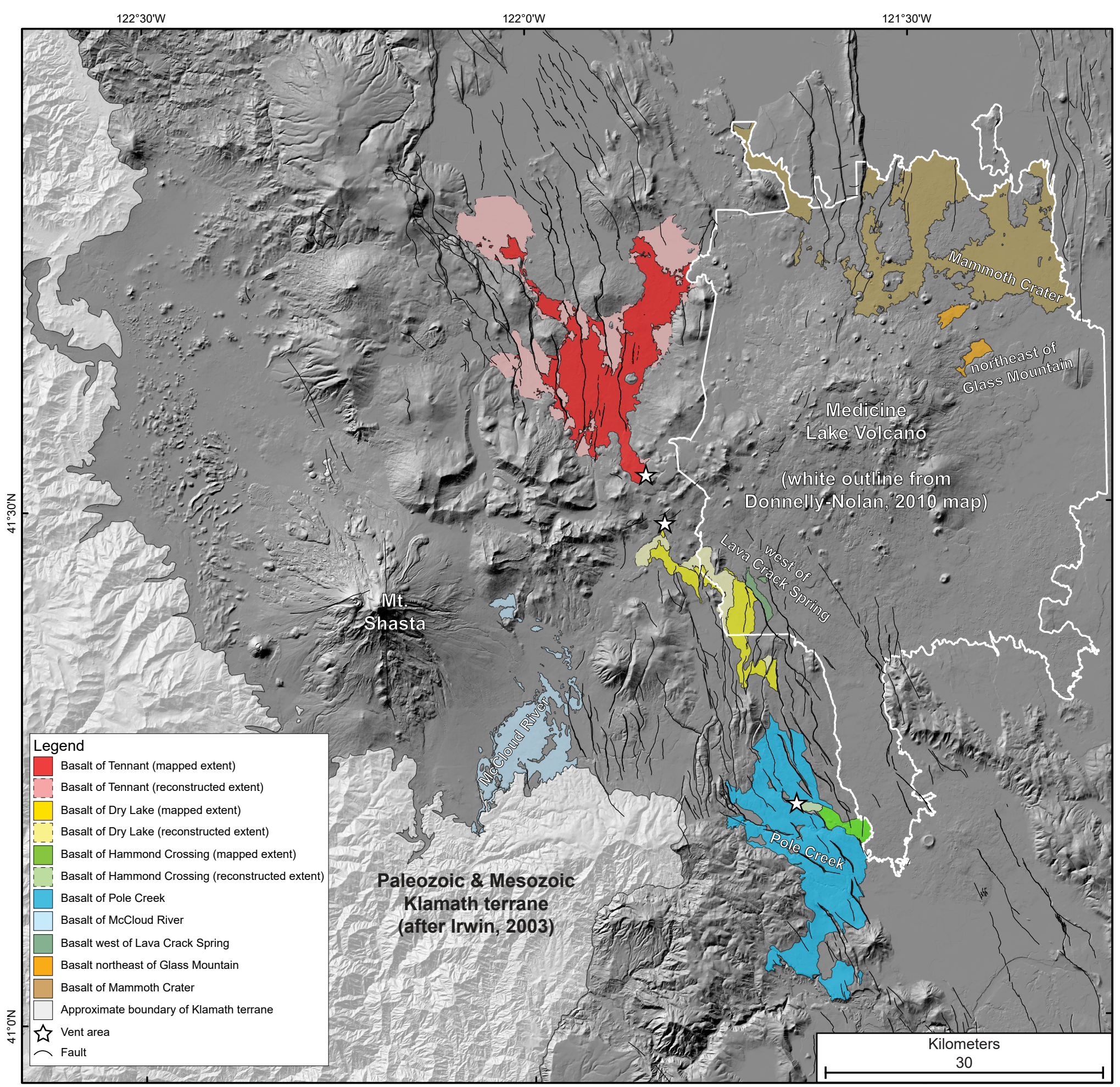

Figure S5 